Artikel Riset

DOI : $10.33751 /$ jf.v8i2.1573
Fitofarmaka Jurnal Ilmiah Farmasi

Vol.8, No.2, Desember 2018

p-ISSN : 2087-9164 e-ISSN : 2622-755X

\title{
PENETAPAN KADAR FLAVONOID DAN AKTIVITAS ANTIMIKROBA EKSTRAK ETANOL KULIT BAWANG MERAH (Allium cepa L.) TERHADAP Staphylococcus aureus
}

\author{
Trirakhma Sofihidayati, Fitria Dewi Sulistiyono, Bina Lohita Sari \\ Program studi Farmasi, FMIPA, Universitas Pakuan, Bogor \\ Email : sofihidayati9@gmail.com
}

Disetujui : 2 Desember 2018

\begin{abstract}
ABSTRAK
Bawang merah (Allium cepa L.) merupakan salah satu komoditas sayuran penting di Indonesia dan banyak digunakan sebagai bahan pengobatan tradisional. Kulit bawang dianggap sebagai limbah, tetapi ternyata pada kulit bawang merah terkandung berbagai bahan alami dengan nilai fungsional tinggi. Bawang merah dan kulitnya kaya akan senyawa seperti senyawa flavonoid dan organosulfur (allicin) yang bertindak sebagai antibakteri. Penelitian ini bertujuan untuk menentukan kadar flavonoid ekstrak etanol $70 \%$ kulit bawang merah dari hasil ekstraksi metode Microwave Assisted Extraction (MAE) dan menentukan aktivitasnya terhadap bakteri Staphylococcus aureus. Uji aktivitas ditentukan pada konsentrasi ekstrak 20, 40, 60, 80 dan100\% dengan mengukur lebar daerah hambat (LDH) menggunakan metode difusi agar. Hasil penelitian ini menunjukkan ekstrak etanol kulit bawang merah mengandung flavonoid sebesar 14,57 \% dan uji aktivitas antibakteri menghasilkan lebar daerah hambat berturut-turut sebesar 18,00;19,50;19,50;22,00 dan 21,50 mm.
\end{abstract}

Kata kunci: Kulit bawang merah, flavonoid, metode MAE, Staphylococcus aureus

\section{DETERMINATION OF FLAVONOID CONTENT AND ANTIMICROBIAL ACTIVITY OF ONION PEEL (Allium cepa L.) ETHANOLIC EXTRACT AGAINST Staphylococcus aureus}

\begin{abstract}
Onion (Allium cepa L.) is a valuable agricultural commodity in Indonesia and usually was used as traditional medicine for its therapeutic properties. Onion peel is an abundant a waste product that is easily found in local market. Many research results show that onion skin contains various natural ingredients with high functional values such as flavonoid and organosulfur (allicin) compounds that act as an antibacterial agent. This research aims to determine the flavonoid content of ethanol $70 \%$ extract onion peel resulted from Microwave Assisted Ectraction (MAE) method. The antibacterial activity against Staphylococcus aurerus was determined at concentration of $20,40,60,80$ and $100 \%$ with measure the width of the growth inhibition zone in agar diffusion. This research result that onion peel ethanol extract of flavonoid content was $14.57 \%$ and antibacterial activity result the growth inhibiton zone was 18.00; 19.50; $19.50 ; 22.00$ dan $21.50 \mathrm{~mm}$.
\end{abstract}

Keywords: Onion peel, flavonoid, MAE method, Staphylococcus aureus 


\section{PENDAHULUAN}

Bawang merah (Allium cepa L) merupakan tanaman pangan yang dapat digunakan untuk mengobati dan mencegah penyakit yaitu sebagai antidiabetes, anti osteoporosis, antikanker, antioksidan, antidiare, antialergi dan antibakteri (Jose dan Krishnakumar, 2017). Beberapa penelitian menunjukkan perbedaan struktur pada golongan senyawa flavonoid menghasilkan aktivitas fisiologis yang berbeda (Shi et al., 2016). Kandungan tertinggi pada bawang merah yaitu flavonoid kuersetin yang dapat mengobati katarak, penyakit jantung dan kanker. Sedangkan senyawa organosulfur dapat menurunkan tekanan darah dan kolesterol (Arora et al., 2017). Senyawa utama pada ekstrak bawang merah adalah kuersetin dan glikosida $\left(3,4^{\prime}\right.$ di- dan 4'-glikosida), juga isorhamnetin monoglikosida, dan kaempferol monoglikosida (Skerget et al., 2009). Kandungan senyawanya lainnya adalah antosianin yang memberikan warna merah atau ungu pada beberapa varietas dan flavonol (kuersetin) menghasilkan warna kuning dan coklat (Ifesan, 2017).

Saat pengolahan bawang merah, kulit biasanya dipisahkan dari umbi dan dibuang sehingga menjadi limbah. Beberapa penelitian terhadap ekstrak yang diperoleh dari limbah kulit bawang merah menunjukkan bahwa secara signifikan ekstrak kulit bawang merah mengandung flavonoid dengan kadar lebih tinggi dibandingkan dengan bagian yang biasa dikonsumsi (Skerget et al., 2009).

Hasil optimasi kadar flavonoid dengan metode ekstraksi konvensional menggunakan pelarut etanol $80 \%$ selama 60 menit menghasilkan kadar 40,35 mg SK/g berat kering kulit bawang merah (Viera et al., 2017). Sedangkan aktivitas antibakteri suspensi metanol 1000 ppm dan suspensi air terhadap $S$. aureus menghasilkan daerah penghambatan terbesar yaitu 29 dan $23 \mathrm{~mm}$ (Eltaweel, 2013).

Salah satu metode ekstraksi modern, yaitu Micowave Assited Extraction (MAE), yang memanfaatkan radiasi gelombang mikro melalui pemanasan pelarut, terbukti lebih efektif dari segi waktu ekstraksi dan kadar rendemen yang dihasilkan lebih besar dibandingkan dengan metode ekstraksi konvensional (Jain, et al. 2009; Gharekhani, 2012).

Penelitian ini bertujuan untuk menentukan kadar flavonoid dengan metode $\mathrm{AlCl}_{3}$ dan aktivitas antibakteri $S$. aureus ekstrak etanol $70 \%$ hasil ekstraksi dengan metode MAE.

\section{METODE PENELITIAN}

Alat

Alat-alat yang digunakan diantaranya microwave (Samsung TDS), oven (Memmert), grinder, ayakan mesh 40, tanur (Vulcan A- 55), vaccuum evaporator, Moisture balance, dan peralatan gelas.

\section{Bahan}

Bahan yang akan digunakan adalah kulit bawang merah, kloroform, asam sulfat, serbuk Mg, amonia, pereaksi Dragendorff, pereaksi Mayer, pereaksi Wagner, asam klorida, amil alkohol, besi (III) Klorida, asam asetat anhidrat.

\section{Pembuatan Simplisia.}

Kulit bawang merah yang diperoleh dari pasar yang berasal dari petani bawang merah daerah Brebes, Jawa Tengah. dikeringkan dengan cara diangin-angin. Simplisia yang telah kering disortasi, diblender sampai halus menjadi serbuk, dan diayak menggunakan ayakan mesh 40 .

Rendemen simplisia $=\frac{\text { Bobot akhir }}{\text { Bobot awal }} \times 100 \%$

\section{Karakteristik Simplisia}

Pemeriksaan karakteristik simplisia yang dilakukan meliputi pemeriksaan kadar air dan kadar abu dari simpisia.

\section{Penetapan Kadar Abu}

Sebanyak \pm 2 gram kulit bawang merah dipijar sampai arang habis, didinginkan, dan ditimbang. Pemijaran dilakukan berulang kali hingga diperoleh bobot yang tetap. 
Kadar abu $=\frac{(\text { Bbt krus akhir })-(\text { Bbt awal })}{\text { Bbt simplisia serbuk }} \times 100 \%$

\section{Penetapan Kadar Air}

Penetapan kadar air simplisia kulit bawang merah dilakukan menggunakan Moisture Balance.

$$
\text { Kadar Air }=\frac{\text { cawan setelah }- \text { cawan sebelum }}{1 \text { gram simplisla }} \times 100 \%
$$

\section{Analisis Fitokimia Kulit Bawang Merah}

Analisis fitokimia simplisia dan ekstrak meliputi pemeriksaan golongan senyawa alkaloid, flavonoid, tanin dan saponin.

\section{Identifikasi Flavonoid}

Sejumlah serbuk kulit bawang merah ditambah dengan air, dipanaskan selama lima menit selanjutnya ditambah beberapa tetes $\mathrm{HCl}$ pekat. Kemudian ditambahkan 0,2 g bubuk Mg. Hasil positif ditunjukkan dengan timbulnya warna merah magenta.

\section{Identifikasi Alkaloid}

Sejumlah serbuk kulit bawang merah ditambahkan air, dihaluskan lagi disaring. Filtrat kemudian ditambahkan asam sulfat $2 \mathrm{~N}$ sebanyak 10 tetes, dikocok kemudian dibiarkan beberapa saat sampai terbentuk dua lapisan. Lapisan atas dianalisis dengan menggunakan pereaksi Dragendorff. Terbentuknya endapan merah jingga menunjukkan bahwa contoh tersebut mengandung alkaloid.

\section{Uji Saponin}

Serbuk kulit bawang merah dimasukkan ke dalam tabung reaksi, ditambah air suling sehingga terendam, dididihkan selama 2-3 menit, dan selanjutnya didinginkan, kemudian dikocok kuat-kuat selama beberapa menit, hasil positif ditunjukkan dengan terbentuknya buih yang stabil (Sangi dkk, 2008).

\section{Uji Tanin}

Sejumlah serbuk kulit bawang merah ditambah air sampai terendam. Larutan kemudian dipindahkan kedalam tabung reaksi dan ditambahkan 2-3 tetes larutan $\mathrm{FeCl}_{3} 1 \%$. Hasil positif ditunjukkan dengan terbentuknya warna hitam kebiruan atau hijau (Sangi dkk., 2008).

\section{Pembuatan Ekstrak Metode MAE}

Sebanyak $50 \mathrm{~g}$ serbuk kulit bawang merah dimasukkan ke dalam erlenmeyer dan ditambahkan etanol $70 \%$ dengan perbandingan 1:10 kemudian dimasukkan ke dalam microwave dan diradiasi secara berkala (radiasi 1 menit dan 2 menit dimatikan) dengan total waktu radiasi 4.5 menit. Hasil ekstraksi didiamkan sampai suhu kamar, disaring dan filtratnya diuapkan hingga menjadi ekstrak kental (Quan et al., 2006)

Rendemen Ekstrak = $\frac{\text { Bobot ekstrak yang diperoleh }}{\text { Bobot simplisia }} \times 100 \%$

\section{Penentuan Kadar Flavonoid}

Ditimbang sebanyak $50 \mathrm{mg}$ ekstrak kulit bawang merah lalu dilarutkan dalam 50 $\mathrm{ml}$ air. Kemudian dipipet $1 \mathrm{ml}$ ekstrak dan di masukkan dalam labu ukur, ditambahkan 15 $\mathrm{ml}$ air, $1 \mathrm{ml} \mathrm{AlCl} 310 \%, 1 \mathrm{ml}$ Natrium asetat dan ditepatkan sampai tanda tera. Larutan dikocok sampai homogen lalu diinkubasikan selama 30 menit. selanjutnya diukur absobansinya pada panjang gelombang maksimum menggunakan Spektrofotometer UV (Chang et al., 2002). Kadar flavonoid dalam ekstrak dapat dihitung dengan mengunakan persamaan regresi kurva standar kuersetin.

$$
\begin{aligned}
& \% \text { Kadar }= \\
& \frac{\text { ppm } \times \text { volume } \times f p \times 10-3}{\text { gr bobot simplisia }} \times 100 \%
\end{aligned}
$$

\section{Penentuan aktivitas antimikroba \\ Persiapan Alat}

Semua alat gelas disterilisasi menggunakan oven dengan suhu $160^{\circ} \mathrm{C}$ selama 2 jam. Bahan cair dan medium disterilisasi menggunakan autoklaf suhu $121^{\circ} \mathrm{C}$ selama 15 menit. Alat bukan gelas seperti jarum ose disterilkan menggunakan alkohol 70\% kemudian dibakar dengan api sampai alkohol tidak tersisa lagi (Hadioetomo, 1993). 


\section{Pembuatan Medium}

Medium bakteri yang digunakan adalah Nutrien Agar (NA). Medium yang sudah homogen kemudian disterilisasi menggunakan autoklaf.

\section{Pembuatan dan Pengenceran Suspensi mikroba}

Bakteri yang telah diremajakan diambil menggunakan jarum ose kemudian masukkan kedalam tabung reaksi berisi $\mathrm{NaCl}$ fisiologis steril. Larutan divorteks sampai diperoleh kekeruhan sama dengan standar Mc. Farland 0,5 yaitu sama dengan $10^{9} \mathrm{CFU} / \mathrm{ml}$ atau berwarna putih keruh. Larutan ini merupakan larutan induk Mc. Farland.

Suspensi bakteri yang digunakan adalah suspensi yang mengalami pengenceran 1: $10^{6}$. Suspensi kemudian diberi larutan induk Mc. Farlan kemudian dihomogenkan (Hadioetomo, 1993).

\section{Pengujian Lebar Daerah Hambat (LDH)}

Pengujian LDH dilakukan dengan menggunakan kertas saring Whattman steril. Kertas kemudian dimasukkan ke dalam ekstrak dengan berbagai konsentrasi dan kontrol negatif lalu dikeringkan. Kosentrasi ekstrak yang digunakan adalah 20, 40, 60, 80 dan $100 \% \mathrm{~b} / \mathrm{v}$ dengan kontrol positif amoksilin $0,01 \%$ dan kontrol negatif DMSO. Kertas cakram yang telah siap dimasukkan ke dalam media, dan diinkubasi pada suhu $37{ }^{\circ} \mathrm{C}$ selama 24 jam. Penentuan lebar daerah hambat (LDH) dilakukan dengan menghitung diameter penghambatan atau zona bening yang terbentuk disekitar kertas cakram menggunakan jangka sorong seperti terlihat pada Gambar 1 (Kumalasari, 2012).

Gambar 1. Pengujian metode difusi cakram

$$
L D H=\frac{D D H-d i s k}{2}
$$

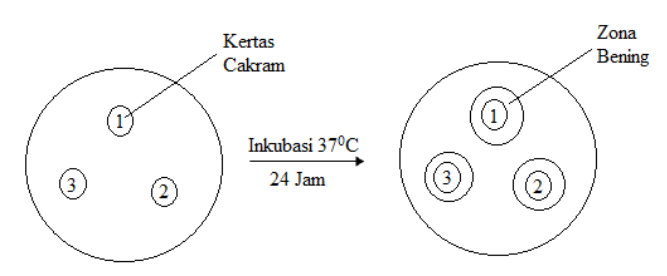

Keterangan :

LDH : Luas Daerah Hambatan

DDH :Diameter Daya Hambat (cm)

Disk : Ukuran kertas cakram (cm)

\section{HASIL DAN PEMBAHASAN}

Pengujian fitokimia dilakukan untuk mengetahui senyawa-senyawa yang terkandung pada ekstrak kulit bawang merah. Hasil uji fitokimia ekstrak kulit bawang merah (Tabel 1) menunjukkan bahwa ekstrak tersebut mengandung senyawa alkaloid, flavonoid, tanin dan saponin.

Tabel 1. Uji Fitokimia Serbuk dan Ekstrak Bawang Merah

\begin{tabular}{llcc}
\hline No & Senyawa & Serbuk & Ekstrak \\
\hline 1 & Flavonoid & + & + \\
2 & Alkaloid & + & + \\
3 & Tanin & + & + \\
4 & Saponin & + & + \\
\hline
\end{tabular}

Tabel 2. Hasil Uji Karakteristik Simplisia dan Ekstrak

\begin{tabular}{clcc}
\hline No & Karakteristik & $\begin{array}{c}\text { Simplisia } \\
(\boldsymbol{\%})\end{array}$ & $\begin{array}{c}\text { Ekstrak } \\
(\boldsymbol{\%})\end{array}$ \\
\hline 1 & Kadar air & 8,161 & 4,521 \\
2 & Kadar abu & 3,277 & 7,878 \\
\hline
\end{tabular}

Karakteristik simplisia yang meliputi penetapan kadar abu dan kadar air dilakukan untuk mengetahui kualitas simplisia sehingga kriteria umum kualitas simplisia yang digunakan untuk penelitian ini dapat terpenuhi. Kadar abu menunjukkan komposisi unsur-unsur anorganik penyusun simplisia baik yang bersifat abu fisiologis seperti magnesium, natrium dan kalsium dalam bentuk trioksida, dan abu non fisiologis seperti silika, tanah. Hasil penetapan kadar air menunjukkan bahwa simplisia memenuhi persyaratan kadar air yaitu di bawah 10\% (Depkes RI, 1985).

Dari hasil ekstraksi simplisia kulit bawang merah yang dilakukan dengan metode MAE menggunakan pelarut alkohol $70 \%$ didapat rendemen ekstrak sebesar 9,792\%. Tampilan ekstrak kental kulit bawang merah dapat dilihat pada Gambar 2 . 


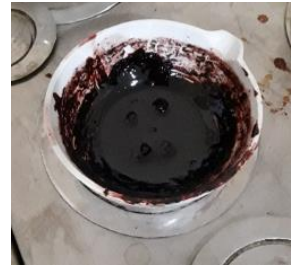

Gambar 2. Ekstrak kental kulit bawang merah

\section{Penetapan Kadar Flavonoid}

Hasil penentuan panjang gelombang maksimum dari kuersetin adalah $431 \mathrm{~nm}$. Dan dari kurva kalibrasi diperoleh persamaan regresi linier $\mathrm{y}=0,0773 \mathrm{x}-$ 0,0025 dengan nilai koefisien korelasi $(\mathrm{R})=0,9993$. Nilai $\mathrm{R}$ mendekati 1 menunjukkan bahwa kurva kalibrasi berupa grafik linier dan terdapat hubungan antara konsentrasi larutan kuersetin dengan nilai serapan (A).

Kadar flavonoid ekstrak kulit bawang merah dengan standar kuersetin adalah ratarata sebesar $14,58 \%$. Kuersetin digunakan sebagai senyawa standar mengacu pada penelitian sebelumnya yang mengkonfirmasi bahwa kuersetin adalah salah satu senyawa golongan flavonoids ada pada ekstrak kulit bawang merah (Soemarie, 2016).

\section{Hasil Penentuan Aktifitas Antibakteri}

Hasil pengujian ekstrak kulit bawang merah terhadap bakteri $S$. aureus yang ditumbuhkan pada media nutrien agar menunjukkan bahwa ekstrak memiliki aktifitas antibakteri dengan kemampuan yang berbeda disetiap konsentrasi seperti pada Tabel 3.

Tabel 3. Lebar Daerah Hambat Ekstrak Bawang Merah Terhadap S. aureus

\begin{tabular}{ccc}
\hline No. & $\begin{array}{c}\text { Konsentrasi } \\
(\% \mathrm{~b} / \mathrm{v})\end{array}$ & $\begin{array}{c}\text { Zona hambat } \\
(\mathrm{mm})\end{array}$ \\
\hline 1 & 5 & 14,0 \\
2 & 10 & 15,5 \\
3 & 15 & 16,0 \\
4 & 20 & 19,0 \\
5 & 25 & 19,5 \\
6 & $\mathrm{~K}(+)$ & 31,5 \\
7 & $\mathrm{~K}(-)$ & 0 \\
\hline
\end{tabular}

Data dari penelitian ini sejalan dengan hasil penelitian sebelumnya yang menunjukkan adanya aktifitas antibakteri kulit bawang merah terhadap bakteri $S$. aureus (Misna dan Diana, 2016).

\section{SIMPULAN}

Penentuan kadar flavonoid ekstrak etanol $70 \%$ kulit bawang merah sebesar $14,57 \%$ dan aktivitas antibakteri ekstrak dengan konsentrasi 20, 40, 60, 80 and $100 \%$ terhadap $S$. aureus menghasilkan lebar daerah hambat berturut-turut sebesar 18.0, $19.5,19.5,22.0$ dan $21.5 \mathrm{~mm}$.

\section{DAFTAR PUSTAKA}

Arora, E.K., Sharma, V., Khurana, A., Manchanda, A., Sahani, D.K.S., Albraham, S., Kundu, D., Gupta, H., Chiru, L.B.C., Sharma, N., Garg, N., Jomy, S. 2017. Phytochemical analysis and evaluation of antioxidant potential of ethanol extract of Allium cepa and ultra-high homoeopathic dilutions available in the market: A comparative study. Indian Journal of Research of Homopoeopathy. 11(2): 89-94.

Chang, C.C., Yang, M.H., Wen, H.M. dan Chernn J.C. 2002. Estimation of total flavonoid content in propolis by two complementary colorimetric methods. Journal of Food and Drug Analysis. 178- 182.

Delazar, A. Hamedeyaz N.L. dan Sarker SD. 2012. Microwave-assisted extraction in natural products isolation methods. Molecular Biology. 864:89-115.

Departemen Kesehatan Republik Indonesia. 1985. Cara Pembuatan Simplisia. Direktorat Jenderal Pengawasan Obat dan Makanan, Jakarta. 10-11.

Eltaweel, M. 2013. International Conference on Chemical, Agricultural and Medical Sciences (CAMS-2013). Kuala Lumpur. Malaysia. 60-61.

Ifesan, B.O.T. 2017. Chemical composition of onion peel (Allium cepa) and its ability to serve as a preservative in cooked beef. International Journal of 
Sciece and Research Methodology. 7(4): 25-34.

Jose, S. dan Krishnakumar K. 2017. A review on phytochemical and pharmacological studies on Allium cepa. Asian Journal of Pharmaceutical Analysis and Medicinal Chemistry. 5(1), 2017, 32 - 36.

Misna, M. dan K. Diana. 2016. Aktivitas antibakteri ekstrak kulit bawang merah (Allium cepa L.) terhadap bakteri Staphylococcus aureus. Galenika Journal of Pharmacy. 2 (2) : 138 144.

Shi, G-Q., Yang, J., Liu, J., Liu, S-N., Song, H-X., Zhao, W-E., Liu, Y-Q. 2016. Isolation of flavonoids from onion skin and their effects on K562 cell viability. Bangladesh J. Pharmacol. 11: S18S25.

Skerget, M., Majhenic, L., Bezjak, M., Knez Z. 2009. Antioxidant, radical scavenging and antimicrobial activities of red onion (Allium cepa L.) skin and edible part extracts. Chem Biochem Eng Q., 23(4): 435-444.

Soemarie, Y.B. 2016. Uji aktivitas antiinflamasi kuersetin kulit bawang merah (Allium cepa L.) pada mencit putih jantan (Mus musculus). Jurnal Ilmiah Ibnu Sina. 1(2): 163-172.

Viera, V.B., Piovesan, N., Rodrigues, J.B., Mello, R. de O., Prestes, R.C., Santos, R.C. Vdos, Vaucher, R. de A., Hautrive, T.P., Kubota, E.H. 2017. International Food Research Journal. 24(3): 990-999. 